BILBAO

\section{9}

R. Lim', M.L. Lim', S. Thangavelautham .

ISingapore General Hospital, Department of Anaesthesiology, Singapore, Singapore.

\title{
COMBINED SPINALEPIDURAL ANAESTHESIA FOR EMERGENCY BOWEL RESECTION IN A PATIENT WITH A LARGE LUNG TUMOUR
}

\section{INTRODUCTION}

Intrathoracic masses require special anaesthetic consideration as they may cause mechanical compression on the airways or the great vessels, possibly resulting in acute respiratory and haemodynamic insufficiency (1). These effects can be caused or worsened by sedation and paralysis during induction of general anaesthesia (GA) and/or changes in position during surgery (2). We describe a case of successful combined spinalepidural (CSE) for laparotomy in a patient with a large lung mass, thereby avoiding $\mathrm{GA}$.

\section{CASE REPORT}

An 80-year-old female with a past medical history of rheumatoid arthritis, hyperlipidaemia and osteoporosis was admitted for incarcerated right inguinal hernia with bowel ischaemia. She was listed for emergency open repair of right inguinal hernia keep in view bowel resection and stoma. Incidentally, she had a newly discovered right upper lung mass measuring $7.4 \mathrm{~cm}$ with compression on the mediastinum including the superior vena cava.

CSE was done at L3/4 in the right lateral position. Intrathecal $2.5 \mathrm{ml}$ of $0.5 \%$ heavy Bupivacaine with $15 \mathrm{mcg}$ Fentanyl was given. The epidural catheter was inserted and secured and the patient was sedated with intravenous propofol infusion. Surgery began with an inguinal skin incision 15 minutes after CSE. Epidural top-up of $2 \mathrm{ml} 0.75 \%$ Ropivacaine was given 20 and 60 minutes into the surgery. $15 \mathrm{~cm}$ of unhealthy small bowel was resected and an anastomosis done. The patient remained comfortable and haemodynamically stable throughout the entire $2 \mathrm{~h}$ surgery.

She was discharged to high dependency after a period of observation in the recovery area. Postoperative analgesia was ensured with a continuous epidural infusion of $0.2 \%$ Ropivacaine with $2 \mathrm{mcg} / \mathrm{ml}$ Fentanyl at $6-8 \mathrm{ml} / \mathrm{h}$ for 72 hours. The catheter was removed on postoperative day 3 and she was discharged home well on postoperative day 6 .

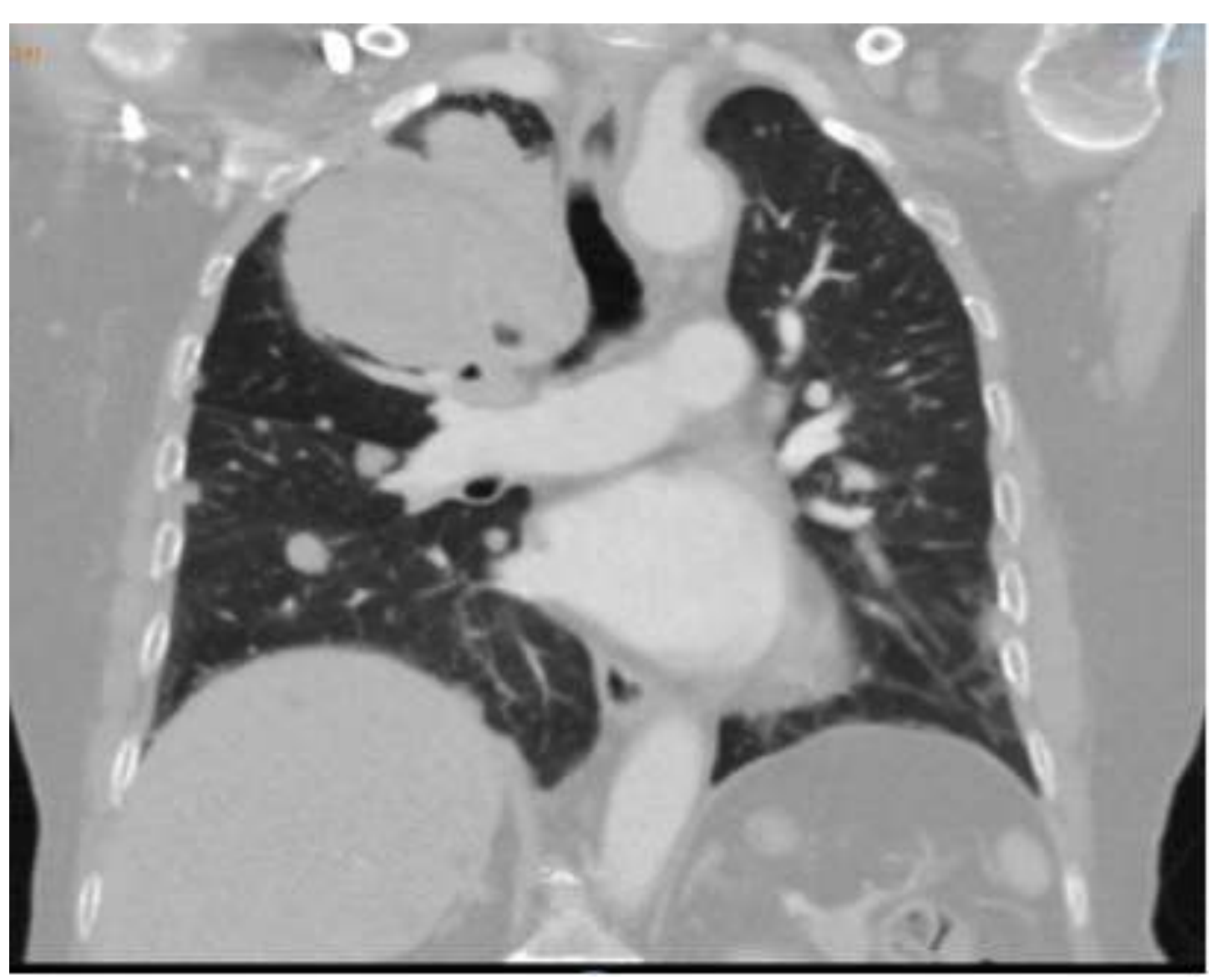

Image 1: CT Thorax showing the large right upper lobe mass with pressure effect on the trachea and superior vena cava.

\section{DISCUSSION}

While there is time for preoperative investigations and optimization in an elective surgery, there was no such luxury of time in this case. Combined spinal-epidural (CSE) anaesthesia alone without GA for laparotomy has been reported in the literature in case reports $(3,4)$. There is also evidence that epidural anaesthesia is associated with a lower risk of postoperative pulmonary complications such as pneumonia (5). This is an anaesthetic technique that should be considered for patients requiring emergency lower abdominal or pelvic surgeries who have intrathoracic or mediastinal masses with the risk of mass effect under GA.

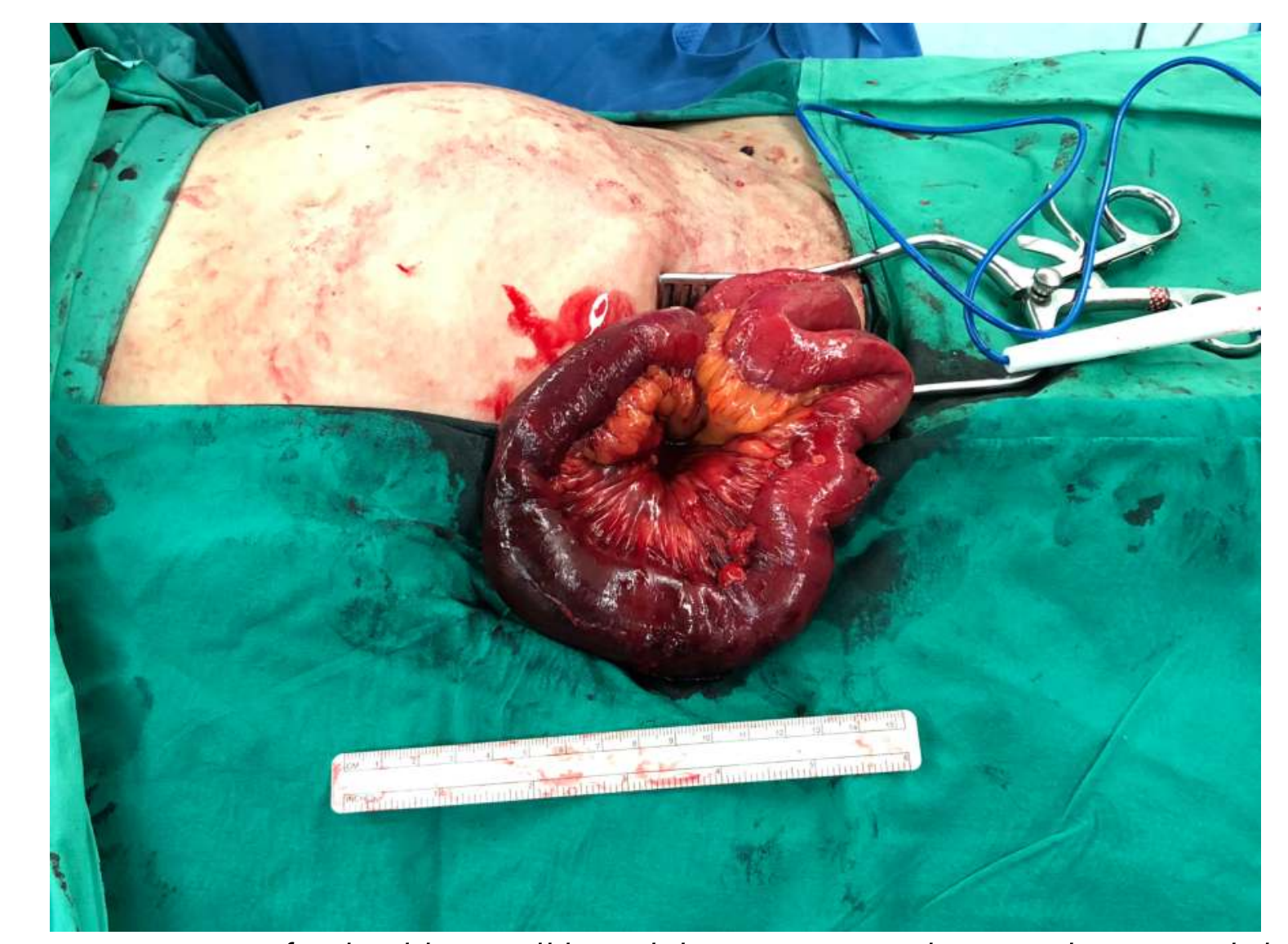

Image 2: Loop of unhealthy small bowel that was resected via a right inguinal skin incision

(1) Blank RS, de Souza DG. Anaesthetic management of patients with an anterior mediastinal mass. Can J Anesth (2011) 58: 853

(2) Erdos G, Tzanova I. Perioperative anaesthetic management of mediastinal mass in adults. EurJ Anaesthesiol (2003) Aug;26(8):627-32

(3) Mai R, Meterissian S, Schricker T. Combined spinal-epidural anaesthesia for sigmoid resection in a patient with severe COPD. Case Rep Clin Pract Rev (2003) 4(2): 169-172

(4) Imbelloni LE, Fornasari M, Fialho J. Combined spinal-epidural anaesthesia during colon surgery in a high-risk patient. Revista Brasileira de Anestesiologia (2009) 59(6): 743-745

(5) Popping D, et al. Protective effects of epidural anaesthesia on pulmonary complications after abdominal and thoracic surgery. Arch Surg (2008) 143(10): 990-999

PATIENTS. AT THE HE $O$ RT OF ALL WE DO. 